WORKFORCE ISSUES

\title{
A case study exploring the ethical and policy dimensions of allocating acute care resources to a dying patient
}

\author{
Mary Cooke PhD, PGCE, RN, CM \\ Lecturer, Acute and Critical Care Nursing Department, School of Nursing and Midwifery, University of Sheffield, Bartolome \\ House, Sheffield, UK
}

Ciarán Hurley MA, RN, BMedSci, PGDip

Lecturer, Acute and Critical Care Nursing Department, School of Nursing and Midwifery, University of Sheffield, Bartolome House, Sheffield, UK

Submitted for publication: 9 August 2006

Accepted for publication: 13 November 2006

\section{Correspondence:}

Ciarán Hurley

Acute and Critical Care Nursing Department School of Nursing and Midwifery

University of Sheffield

Bartolome House

Winter Street

Sheffield S3 7ND

UK

Telephone: 01142229740

E-mail: ciaran.hurley@sheffield.ac.uk
COOKE M \& HURLEY C (2008) Journal of Clinical Nursing 17, 1371-1379

A case study exploring the ethical and policy dimensions of allocating acute care resources to a dying patient

Aims. We aimed to identify policy, process and ethical issues related to allocation of National Health Service resources when patients with end-of-life illness are referred to acute care services.

Background. Sharing healthcare decisions denotes a different partnership between professionals and patients when patients are empowered to define their needs. Implementation of a transition from professional to patient decision-making appears to be dependent upon its interpretation by personnel delivering care using the local trust policy. The outcome of this is a reformation of responsibility for budget allocation, choice of acute care provider and selecting services, currently in the realm of primary care; be it the general practitioner, community practitioners, or the patient.

Design. We used a 'lens' approach to case study analysis in which the lens is constructed of a model of policy analysis and four principles of biomedical ethics. A patient's decision to decline care proposed by an Accident and Emergency department nurse and the nurse's response to that decision expose a policy that restricts the use of ambulance transport and with that, flexibility in responses to patients' decisions.

Findings. End-of-life care partnership decisions require sensitivity and flexibility from all healthcare practitioners. We found that policy-based systems currently used to deliver care across the primary care - hospital care border are far from seamless and can lead to foreseeable problems.

Conclusions. Health professionals responsible for the care of a patient at the end of life should consider the holistic outcomes of resource allocation decisions for patients.

Relevance to clinical practice. Government and health professional agenda suggest that patients should be given a greater element of control over their healthcare than has historically been the case. When patients take responsibility for their decisions, 
healthcare personnel should recognize that this signals a shift in the nature of the professional-patient relationship to one of partnership.

Key words: case study research, end-of-life, Ethics, nurses, nursing, policy

\section{Introduction}

The UK's National Health Service (NHS) is frequently criticized for its use of complex policies and structures that often distance public understanding and deter people from gaining access to health care in the UK (Buse et al. 2005). The transitions between primary and secondary care settings can be difficult for patients to navigate and it is often the duty of health professionals to advise patients how to make best use of the service within their individual capacity for locating and accessing health care (Department of Health 1998a,b). The international Code of Ethics for Nurses emphasizes that the focus of concern should be the individual to whom care is delivered and not the service or resources being used (International Council of Nurses 2006). This stance and value base for care delivery is reflected in the Code of Professional Conduct for UK nurses (Nursing and Midwifery Council 2004). Meanwhile patient choice in empowered decision-making is upheld through the Chief Nurse's statements on the Essence of Care (Department of Health 2005).

The delivery of health care is subject to influence from several sources, defined as stakeholders (Buse et al. 2005). Policies sponsor change to local and national government strategies, and health and social care reforms are often the consequence. Such reforms may inadvertently lead to certain groups being disadvantaged by the changes that some policies bring to a once-familiar system while few opportunities to learn from past examples are used (Sanderson 2002). The impact of such reforms can be analysed by a combination of health policy evaluation and ethical analysis to illuminate problems and potential solutions (Buse et al. 2005, Royal College of Nursing 2006). Health policy assumes an ethical standard for political, organizational and social acceptability. Ethical analysis often takes a philosophical stance and we use a combination of utilitarian and deontological philosophies to apply four principles of biomedical ethics in the analysis of the case described in this study (Gillon 1986, Beauchamp \& Childress 2001).

The aim of this case study was to identify policy, process and ethical issues related to allocation of NHS resources when patients with end-of-life illness are referred to acute care services. We use a clinical case from an acute and critical care setting - a British city Accident and Emergency (A\&E) Department - to demonstrate a framework for the analysis of policies for shared decision making and the ethical principles of healthcare provision in the UK. Firstly, the four principles of quality, accountability, equality and partnership are used to test whether policy and recent reforms reduce health inequalities and improve public health (Royal College of Nursing 2006). Then, the ethical principles of justice, autonomy, beneficence and non-maleficence are applied to the case to promote understanding of the effect of such policies on patient care (Gillon 1986, Beauchamp \& Childress 2001). The clinical case is then discussed by using arguments that underlie both policy and ethical points, drawn from the welfare principles of health and social care provision in the UK; that the public deserves a range of high quality, easy to access universal services, free at the point of delivery and funded from progressive taxation.

\section{Literature}

There are three elements to the literature concerning this case study. The key policy issues assume, firstly, that patients and healthcare professionals share decisions and plan acceptable care. Patients who need long-term care will have social- and health-based packages provided by the Primary Care Trust in the community, which may include palliative care. Secondly, people who use $A \& E$ are treated for the immediate acute problem and can expect decisions about their needs to be made and actioned within four hours. Thirdly, all policies have an ethical dimension and an implied cost. Costs of care and policies are related to demand and it is usual though not universal that where demand can be reduced, so can costs.

Policies determining the provision of palliative care in the UK state a preference for care in the patient's home provided from Primary Care Trust resources. Where acute care is required, it is assessed in the hospital, by arrangement between the general practitioner (GP) and the receiving physician in the appropriate acute specialty. Sometimes patients are caught between services if their GP is unavailable and differential diagnosis is required because of new symptoms, or an increase in community support and resources is necessary; in these circumstances a referral to acute services for a diagnosis may be appropriate (Whitfield et al. 2004).

Evaluating the authenticity, meaning, corroboration and reason for documentation is a method of critically assessing documentary sources (Bryman 2004). However, analysis of 
patient-centred clinical policy seeks to define the quality, equality, accountability and partnership aspects of policy implementation and whether or not and why it has achieved its goals (Royal College of Nursing 2006). Most policy arises through ideology and beliefs around health care and systems of provision, stakeholder constituents and needs. The manner in which these are expressed in arenas such as the media and political actions are defined by those in power such as legislators (Buse et al. 2005).

Two common approaches to the analysis of a clinical scenario's ethical dimensions are utility and deontology. Utilitarian ethics award greater moral value to actions whose outcomes produce greater 'happiness' than alternative actions. Deontological methods seek to ascribe moral duties to individuals on the basis of their relationship with other individuals, groups or classes of person. Each has merit in the context of healthcare delivery in the UK; deontology because duties of care are imposed by legislation, common law, professional regulation and public expectation; utility because parts of those imposed duties require healthcare professionals to consider the impact of their work on the individuals in receipt of care (Donoghue V Stevenson [1932], The National Health Service Act 1977, Gillon 1986, General Medical Council 1998, General Medical Council 2001, Nursing and Midwifery Council 2004). It is this combination of utilitarian and deontological approaches to ethical decision making that justify the use of casuistic arguments in the analysis of healthcare ethics; normally risible in both research and philosophical circles because of their reliance on single case analyses and lack of generalizability (Beauchamp \& Childress 2001).

In addition to this combined approach are the 'four principles of biomedical ethics': justice, autonomy, beneficence and non-maleficence. These principles are considered to be universal and, although varied in the level of compulsion that they place upon a person's actions, when a balance is struck that might best achieve all their aims, they can be used to assess the ethical nature of a situation. For the purpose of this case, justice is a matter of deciding a patient's right of access to healthcare services; autonomy relates to the freedom of thought, will and action that the patient is afforded in the situation in which they are described; beneficence is made out when a person rises to the opportunity to do good while nonmaleficence requires consideration of the amount or extent of harm apparent in the outcomes of particular actions (Gillon 1986, Beauchamp \& Childress 2001).

Case law that is pertinent to this study dates back as far as 1932. The precedent set by the House of Lords in Donoghue V Stevenson [1932] imposes upon all citizens of the UK a general duty of care to ensure that the foreseeable outcomes of their actions or omissions are in no way harmful to others. In addition to this general duty of care, obligations are placed on health professionals by the nature of their registration with a professional body; for example, nurses are required to intervene in emergency situations both in and out of the workplace (Nursing and Midwifery Council 2004: clause 8.5) and doctors are required by common law to provide care to people who are brought to their attention, regardless of whether the individual is a registered patient of that doctor (Montgomery 2003).

This casuistic approach is instrumental in the formation of common law and public opinion. Cases that come into the public eye define and re-define consensus and as a result authority arises from the social and legal consensus formed by the doctrine of precedent. This is a valuable process because common law, societal approaches to morality and the execution of a duty of care by health professionals each require interpretation within the context of health policy and healthcare practice, both of which have a normative element to their ontology. Where events occur without being discussed in a public forum, there can be no precedent that has been tested by discussion, decision or judgment and, for that reason, we present this case study.

We offer an opportunity for healthcare professionals to define their own stance on the case; invite them to relate this method of analysing decisions to their local health policy and practice and to reflect on the approach taken by themselves and their orgnanization to patient autonomy and shared decision making. We would particularly like them to consider using this approach in situations of end-of-life care where policy and moral obligation appear to be in conflict.

\section{The case}

In the early hours of a weekend morning, among the typical clients of a large city A\&E: homeless people, victims and perpetrators of alcohol related violence, those complaining of abdominal or chest pains: David (a pseudonym) and his wife, both in their late eighties, presented an unusual request. The couple had arrived late the previous night in A\&E by referral from a locum General Practitioner (physician) who was called when David suffered worsening shortness of breath. Twice in the last four weeks, David had received acute inpatient care for drainage of pleural effusions while in a nearby hospital. David's medical history included ischaemic heart disease, paraplegia following an iatrogenic spinal cord injury and venous leg ulcers. He received a long-term care package from primary and social care services for these problems and lived at home with his wife. Along with the usual baseline physical observations, David had a series of 
electrocardiograms that showed ischaemic changes suggestive of an imminent ischaemic heart attack. From an administrative perspective, David had been in the department for more than three hours and was approaching a point at which government targets dictated that a definitive decision should be made regarding his management and transfer from the A\&E to either be discharged home or dispersed to a receiving ward (The Audit Commission 2001, The National Audit Office 2003, 2004, The Healthcare Commission 2005).

When invited to present his perspective on the possible outcomes of this visit to hospital, David stated that he wanted no more acute treatment. He understood this would probably precipitate his death and that he would like to go home by ambulance as soon as possible, especially if he was likely to die in the near future.

At this point, a contention of views emerged. The nurse coordinating David's care believed that his request for ambulance transport was unreasonable because David had declined the admission to hospital for treatment and was therefore no longer owed a duty of care beyond safe conduct off the premises. The junior doctor (senior house officer) was diverted by the nurse from making a diagnosis and plan for treatment, to certify and document that David had decided to withdraw from treatment and discharge himself from the hospital. This left David and his wife with no other option at that point than to define their responsibility for self-discharge and make their final journey home together in a private hire car or taxi which, they pointed out, was risky and unsuitable.

\section{Case study method of analysis}

Stake (1994) considers the case as an object of study. Yin (1998) offers pragmatic constructs to the manner in which cases differ and as a consequence, frames analysis between and within each case, developing causal relationships with which to create theoretical links between other phenomena. These theorists are frequently used to define and discuss case study method. Scholz and Tietje (2002) go further in their explication of structure and analysis for case study by arguing that complexity affects the case being studied and technique for analysis requires specific approaches to incorporate embedded data best applied to a specific situation. They use data streams from all sources to inform facts of the case and view the data through a lens. In this case, the lens is constructed of the health policy evaluation principles of quality, equality, partnership and reduction of health inequality and the ethical principles of justice, autonomy, beneficence and non-maleficence. The data are 'decomposed' in the lens and 'reformed' to provide a new conception of the problem (Scholz \& Tietje 2002). We applied this method specifically because of the complexity of the case. The streams of factual data arise from policy, ethics, clinical management, professional practice and patient's perceptions of their needs. Table 1 summarizes the analysis of the facts associated with the policy for transporting patients' home from A\&E using the Royal College of Nursing's model of policy evaluation (2006) from the perspectives of the patient, the health professional and the organization. Table 2 summarizes the ethical analysis of the case using the four principles of biomedical ethics from the same perspectives.

\section{Findings of policy analysis}

Factual analysis of this case uses the key points for review. These are that:

1 The patient had been sent to the A\&E with his wife late at night because the locum GP was unable to make a diagnosis without reference to the acute services;

2 The patient, when informed of his health status, made a decision in partnership with his wife and shared this with the clinical staff;

3 The staff reacted negatively to this decision, became defensive and unable to interpret the general policy of refusing a class 1 ambulance to transport a patient to die in his home objectively.

We now look at the policy, evaluating the stakeholder power and the four principles of quality, accountability, equality and partnership (Royal College of Nursing 2006) in relation to the lens method of case study analysis (Scholz \& Tietje 2002). Specific policies examined are (1) the sharing of decision making in principle and (2) the lack of suitable and safe transport for the patient to activate his decision.

The objective to provide quality service has not been met fully in this case, David's safety has been compromised by the lack of provision of suitable transport services and by the failures to deliver care that meets the demands of ethical principles. Although the care delivered to David by the individuals involved would probably meet the standards of the Bolam test (Bolam v Friern Hospital Management Committee 1957, Montgomery 2003), their interpretation of the policy regarding patients' transport is somewhat atomistic and was not explained to David until after a decision had been made that in retrospect was irreversible. The organization has achieved several of the quality aspects of its policy objectives, but nonetheless the outcome has resulted in an unhappy patient whose needs have not been met.

The confidence of the patient and his partner has been reduced by the failure of personnel to adequately justify their refusal to provide the requested service. There are two apparent reasons for this failure. One is a failure of the nurse 


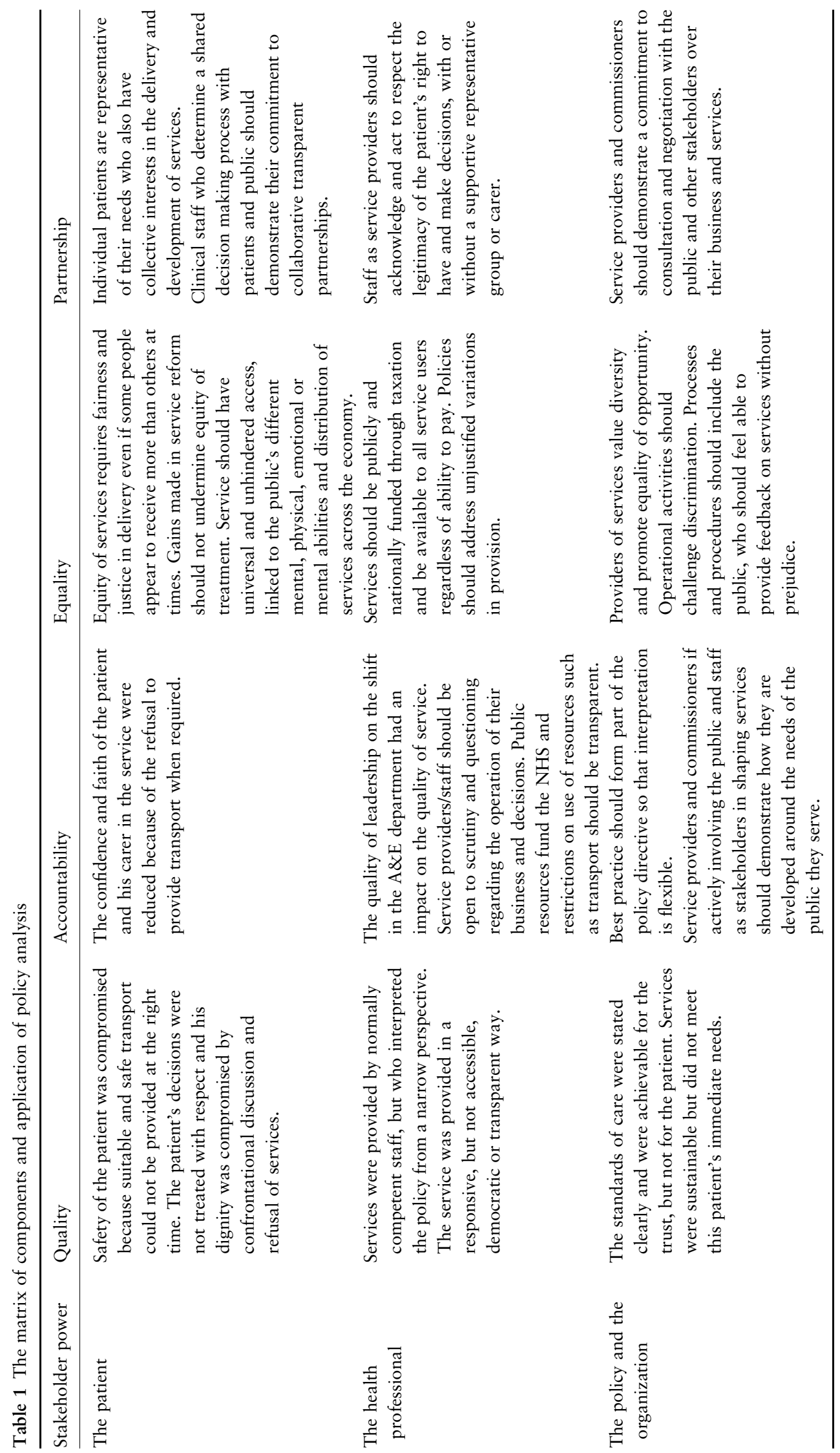




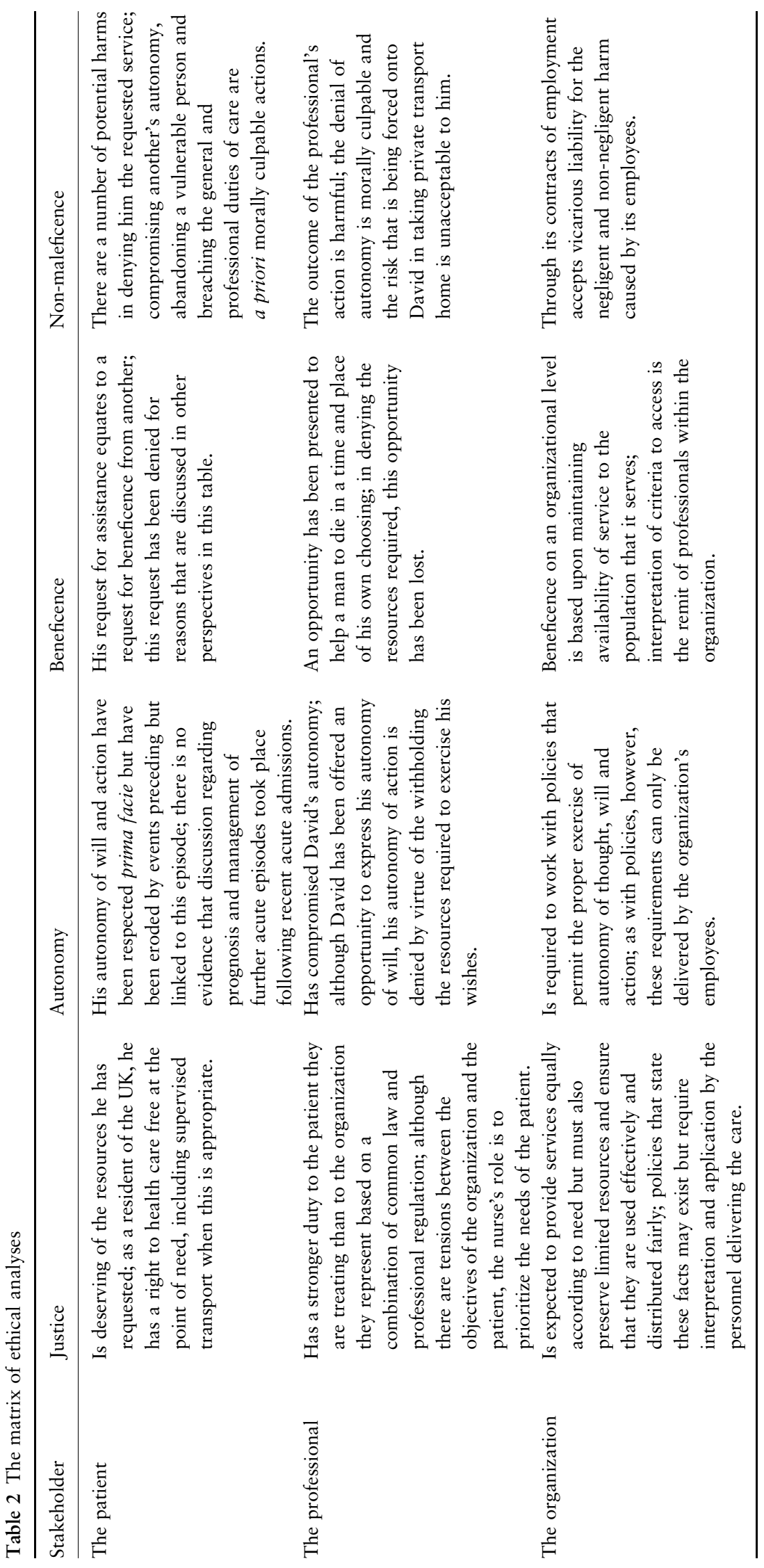


in charge of the shift to monitor and co-ordinate the delivery of high quality services through transparent procedures. An expectation of transparency and accountability to service users arises mainly from the fact that the greatest source of funding for the NHS is the taxpayer's purse. Another is a failure of the organization to create sufficient flexibility in its policies to allow personnel to meet the needs of individuals while still aiming towards an objective of maintaining services for the wider population.

Equality of service requires a distribution that is fair to everyone, not necessarily the same for everyone. Some service users require health services more frequently or require more expensive resources than others. In principle, inequitable access means that the expense of treating the sick is offset by the relatively low costs incurred by the well. Professional roles in the allocation of resources ought to be confined to familiarity with indications, contra-indications and access policies. In this instance, we find that the nurse who has declined David's request and co-ordinated his discharge has failed to recognize the principle of offsetting in this way.

The issue of partnership is interpreted in several ways. From the patient's perspective, there is an expectation of partnership in decision-making that parallels the ethical principle of respect for autonomy. The ability of professionals to solicit patients' opinion, a valid consent and to create plans of care in partnership is an essential element in the fulfillment of this expectation. While there is an expectation that organizations will solicit the opinion and advice of patients and service users when designing and maintaining services, this point has relatively little value for this case.

\section{Findings from ethical analysis}

Through consideration of David's care using the lens approach to case study analysis, there are clear streams of data indicating that there were moral failings in the system that resulted in David being stranded in A\&E and lacking suitable transport home. The findings are derived from the combined consideration of the philosophies of utility and deontology and the four principles of biomedical ethics.

From David's perspective as a UK resident he has a right to healthcare free at the point of need. To his mind, his greatest healthcare need is to get home safely and receive palliative care so that he can die in a time and place of his own choosing. The nurse's response to David's request failed to address issues of justice in the allocation of resources. Although it can be interpreted as forwarding the organization's interest in preserving a limited resource, we have established that a nurse's duty of care is to the patient's needs, not those of the organization (Nursing and Midwifery Council 2004, International Council of Nurses 2006).

In asking David to reflect on his expectations regarding this particular admission to hospital, the nurse has implied an opportunity for David to exercise some level of autonomy. This is a commendable approach to managing patient care but less commendable is the manner in which David's response was managed. There is little value in creating an illusion of autonomy by asking patients about preferences and choices if the resources to meet their individually coined demands are not available to them. It matters not that the limit arises either from differences of opinion between patient and professional, or organizational policies that restrict access to services on the grounds of scarcity.

Issues of beneficence are difficult to isolate in this case. Stating the fact that the general public expects healthcare workers to 'do good things for others' seems either trite or redundant; nonetheless, in this instance the request for beneficent action has been denied. The least culpable interpretation of this denial is that professional and organizational duties of beneficence are best met through the preservation of resources so that they are available for the most deserving. There is difficulty in deciding who ought to identify the most deserving cases and it has already established that it should not be the nurse. The literature regarding health policy suggests that it ought to be an institutional approach that allows flexibility and recognition of individual needs as well as those of the organization.

The requirements of non-maleficence are that actions that will be harmful to others are avoided. In this case, it would require a sublimely altruistic act on David's part to avoid the only potential harm that his request offers, that being to deprive the use of a class I ambulance to the victim of a trauma who may suffer for lack of prompt attention. From the perspective of the professional and the organization, their duty must surely be to the real and present patient and not to the unknown and hypothetical patient. There is clear harm to David as a result of his being denied the use of that ambulance and a duty to consider the needs of the patients that are known to you before those that do not 'exist' in any real sense at the time.

\section{Discussion}

The argument that all duties of care owed to David by the personnel of the A\&E department were discharged the moment he declined the treatment offered to him fails to recognize a number of salient facts. Duties of care are not so clearly or easily limited to time, space and circumstance: there are general duties of care imposed by common law on 
all citizens of England and Wales; a registered nurse or medical practitioner has a professional duty of care to anyone requiring health care that is brought to their attention and there are moral and societal expectations to provide help to vulnerable people. In addition to the duties imposed on individuals, provision of health services under The National Health Service Act 1977 entitles vulnerable people to NHS or local authority transport where the alternatives are deemed to be unsafe. Policies are designed to support all stakeholders in health care; providers and service users alike. As implied above however, the quality of a policy is only as high as its interpretation and application by personnel. The interpretation and implementation of policy by health professionals in this case denied David's rights as an autonomous individual both in legal and in moral terms.

A combined view of the duties of non-maleficence and beneficence suggests that the moral approach to this case would be to meet David's request for transport since to deny it would predictably be detrimental to his own mental and physical wellbeing, may have a negative impact on his wife's approach to health services in the future and would be burdensome upon a private hire car driver if David were to become more unwell or die en route to his home.

The perspective of autonomy reveals several shortcomings in both the immediate and the long-term management of David's care. The creation of an illusory autonomy that crumbles under difference of opinion between patient and professional suggests a lip-service approach to autonomy that does not meet the rigorous demands of professional practice in modern health care. The failure to make thorough discharge plans and to discuss or communicate these to David, his wife and those providing care to him at home appears to have resulted in the needless referral of a dying man to A\&E.

\section{Conclusions}

While nursing considerations are offered in this ethical analysis, other health professionals were involved in David's care pathway. The case management approach taken by the GP and supported by primary care policies each had a strong influence on the various possible outcomes of cross-boundary decisions and options that could have been be selected. Staff in hospital and A\&E departments faced with identifying the best interests of each patient are restricted by resources and limited information available from the patient, GP or community services to inform their assessment and planning of patients' needs and outcomes. The differing patient and professional perspectives combined with implications for policy application offer a matrix for care that could be more positive than the one described here.
By using this particular framework of policy and analysis, we have defined the case on the objective side of the lens, and analysed it by using the four principles of biomedical ethics and the principles of healthcare policy analysis to produce an image that demonstrates deficits in practice. We hope that publication and discussion of these matters will help practitioners to identify areas in which improvements to their own healthcare delivery systems could be made.

\section{Contributions}

Study design: MC, CH; data collection: MC; analysis: MC, $\mathrm{CH}$ and manuscript preparation: $\mathrm{CH}, \mathrm{MC}$.

\section{References}

Beauchamp TL \& Childress J (2001) The Principles of Biomedical Ethics, 5th edn. Oxford University Press, Oxford.

Bolam v Friern Hospital Management Committee (1957) Weekly Law Reports, page 583.

Bryman A (2004) Social Research Methods. Oxford University Press, Oxford.

Buse K, Mays N \& Walt G (2005) Making Health Policy. Open University Press, Berkshire.

Department of Health (1998a) The Health of the Nation - A Policy Assessed. The Stationery Office, London.

Department of Health (1998b) Partnership in Action. The Stationery Office, London.

Department of Health (2005) Essence of Care: Benchmarking for Health. The Stationery Office, London.

Donoghue V Stevenson (1932) Appeal Cases, page 563.

General Medical Council (1998) Seeking Patients' Consent: The Ethical Considerations. General Medical Council, London.

General Medical Council (2001) Good Medical Practice. General Medical Council, London.

Gillon R (1986) Philosophical Medical Ethics. John Wiley \& Sons, London.

International Council of Nurses (2006) Code of Ethics for Nurses. International Council of Nurses, Geneva.

Montgomery J (2003) Healthcare Law. Oxford University Press, Oxford.

Nursing and Midwifery Council (2004) The NMC Code of Professional Conduct: Standards for Conduct, Performance and Ethics. Nursing and Midwifery Council, London.

Royal College of Nursing (2006) Policy Analysis Framework. The RCN Policy Unit, London.

Sanderson I (2002) Evaluation, policy learning and evidence based policy making. Public Administration 80, 1-22.

Scholz RW \& Tietje O (2002) Embedded Case Study Methods: Integrating Quantitative and Qualitative Knowledge. Sage, London.

Stake R (1994) Case studies. In Handbook of Qualitative (Denzin N \& Lincoln Y eds). Research Sage, Thousand Oaks CA.

The Audit Commission (2001) Review of national findings Accident and Emergency. Her Majesty's Stationary Office, London. 
The Healthcare Commission (2005) Acute Hospital Portfolio Review: Accident and Emergency. The Healthcare Commission, London.

The National Audit Office (2004) Facing The Challenge: NHS Emergency Care in England. Report by the Comptroller and Auditor General HC 36 Session 20023-2003: 15th November. Her Majesty's Stationary Office, London.

The National Audit Office (2003) Department of Health: Improving Emergency Care in England. Report by the Comptroller and
Auditor General HC 1075 2003-2004: 13th October. Her Majesty's Stationary Office, London.

The National Health Service Act (1977) Her Majesty's Stationary Office, London.

Whitfield M, Smith K, Thomson R \& Hind D (2004) Palliative Care Review. University of Sheffield, Sheffield.

Yin RK (1998) The abridged version of case study research design and method. In Handbook of Applied Social Research Methods (Bickman L \& Rogg D eds). Sage, London. 